\title{
Psychological Aspects of Realizing Individual Educational Activity of Preschool Children
}

\author{
Likhachyova Ye. N
}

Ogoltsova Ye. G

Bobrova V

Doi:10.5901/mjss.2016.v7n2p251

\begin{abstract}
Determining and systemizing children's typical difficulties in learning the program material of an educational institution, as well as searching for causes of these difficulties emergence. Based on experimental psychological study of informative, emotional and strong-willed and interpersonal spheres as the mechanism of the child's perception of the world around. For the first time there are revealed and systemized the features of the mental processes formation at the preschool age children experiencing difficulties in leaning the program material of an educational institution. There is defined the mechanism of the difficulties emergence that consists in a variable level of the mental processes development. Based on the results of this study there is possible organization of the purposeful psychological and pedagogical assistance to children experiencing difficulties in leaning the program material of an educational institution.
\end{abstract}

Keywords: individual features, preschool age, insufficient level of mental processes formation.

\section{Introduction}

The condition of successful training and educating the children experiencing difficulties in learning the program material owing to individual opportunities connected with the insufficient level of mental processes formation is organization of timely purposeful pedagogical work to them. Training and educating children taking into account their individual opportunities, forming optimum conditions for their development become one of the most important problems of the teaching and educational process. At present the pedagogical work with the studied category of children is complicated by a number of factors (Chova, 2012):

- a low level of early psychological and pedagogical diagnostics of children with the insufficient level of mental processes formation;

- a low level of specialized help to children with the insufficient level of mental processes development at the stage of preschool age;

- violations of the family relationships with a child with the insufficient level of mental processes formation.

The studied category children being in mass conditions of a preschool educational institution puts forward and staticizes a number of problems that demand for the decision (Bardyshevskaya, 2014):

- theoretical and practical definition of the concept "a child experiencing difficulties in assimilation of the preschool educational program owing to individual abilities". The value of the theoretical definition of the specified term is that it is to promote somewhat deeper understanding of the essence of children's mental development. The accuracy of the theoretical approach to the concept "a child experiencing difficulties in assimilation of the preschool educational program owing to the individual abilities" will permit teachers and parents to understand and to explain the reason of this state, to allocate the most essential signs;

- studying and detecting psychological and pedagogical features of the studied category of children in the conditions of mass preschool institutions. The essence and manifestations of the causal factor of the detained option of the child's intellectual development which cornerstone is the insufficient level of the mental processes development, is at present covered in scientific and educational literature on psychiatry, neuropathology, as well as special psychology and defectology (Maryutina, 1994).

The pedagogical practice needs the psychological and pedagogical characteristic of this concept as it is to include the data which are necessary for the tutor for qualified studying, training and educating this category of children in traditional conditions of a preschool educational institution. 


\section{The Analysis of the Latest Researches and Publications}

The analysis of scientific pedagogical literature permitted to reveal that now for most of researchers and practitioners, in relation to this group of children, the keywords became: "unprepared children", "children with poor progress", "weakened children", "children of group of risk", "spoilt children", etc (Presser, 2015).

The wide range of the term concepts is explained by the inaccuracy of its intrinsic characteristic. In our opinion, when determining the concept for these children the main thing is that they, throughout the entire preschool age do not cope with the program requirements of a kindergarten and by the time of entering school they do not reach the necessary level of readiness for training.

\section{Research Methods}

Based on experimental psychological study of informative, emotional and strong-willed and interpersonal spheres as the mechanism of the child's perception of the world around.

\section{Basic Material}

So, by the results of the psychological and pedagogical study of the children of preschool age carried out by us (only 1650 people, among them junior, middle and senior preschool age of 550 children) it is established:

- at children of junior preschool age (29\%) skills of self-service are not developed, they find it difficult to coordinate the actions with actions with others, there is no formation of touch standards. These children find it difficult to understand and designate with a word any property and quality of subjects, they are not able to make generalization, to express a thought in their own words. In their speech development there is noted poor active vocabulary, imperfection of grammatical structures of speech, there is no skill of coordinating the parts of speech, correct use of prepositions. In classes there is registered the weakening of their cognitive interest, a low level of the memory and attention development. In the game activity these children do not communicate with contemporaries, etc.;

- at children of middle preschool age (26\%) in the incomplete volume there are formed the program requirements skills of self-service and cultural and hygienic skills. Communicative skills with contemporaries and with adults are reduced. In the game activity there is noted a low level of skills of role behavior, there is practically no ability to play together with contemporaries. In classes the rate of their activity is slowed down, they need individual organizational stimulation from the tutor. The independent activity in classes is considerably complicated (children perceive tasks very slowly, they are not able to set the purpose before themselves and to reach it);

- at senior preschool age children $(23 \%)$ there is noted the reduced ability to independent activity. The interpersonal relations with contemporaries are unstable and characterized by the absence of friendly relationship and mutual aid. In the children's activity the planning component is complicated, they are also at a loss in self-organization of their actions, as a rule, they do not strive for a positive result in individual and public affairs. In classes these children experience difficulties in classification of generic terms. In speech development there is noted the backing in the vocabulary from the age norm, poor semantic part of speech. The children cannot retell coherently and logically the matter of the work, make independently a story on a picture. Cognitive interests are situational, the level of the development of feelings, perceptions, attention, imagination and thinking is lower than the age level. In classes in mathematics they do not possess the direct and reverse counting, not always understand the principle of obtaining the subsequent number, incorrectly use ordinal numerals, etc.

For the purpose of systematization of children's difficulties in learning the program material of a preschool educational institution we carried out the monitoring research including studying the following parameters (Barandiaran, 2015):

- the development of speech (vocabulary, sound standard of speech, grammatical system of speech, coherent speech);

- fiction (ability to listen to a work of art, to understand the sense of a work of art, to reproduce a work of art, reading by heart a short work of art);

- elementary mathematical representations (quantity, value, orientation in space, geometrical figures, orientation in time); 
- acquaintance with people around (the phenomena of public life, subjects of the immediate environment, a natural phenomenon);

- graphic activity (technology of work with a pencil and a brush, technology of work with clay, technology of work with scissors, paper and glue);

- construction (technology of work with construction materials);

- musical education (listening to music, singing, musical and rhythmic movements);

- game activity (subject role-playing games, outdoor games, didactic games);

- communication and behavior (cultural and hygienic skills, skills of culture of behavior, interpersonal relationships).

The criteria of estimating each of the parameters were based on the tasks and requirements to the level of learning the program material of a certain age period.

The characteristic of the level of assimilating the program by a child was carried out at three levels: a high one which corresponded to 2 points, a middle one - to one point and a low level -0 points. Monitoring showed the presence of children who are not coping with the program requirements of a preschool educational institution, and permitted to reveal the sections of the program material of a preschool educational institution according to which these children experience the greatest difficulties. The data concerning the children who acquired the program material of a preschool educational institution at the low level are presented in Table 1.

Table 1 - Children who cannot cope with the program requirements of the preschool educational establishment, \%

\begin{tabular}{|c|c|c|c|c|c|c|c|c|}
\hline Age & 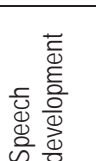 & 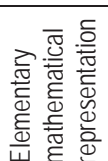 & 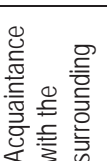 & 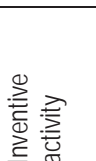 & 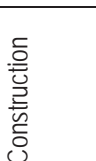 & 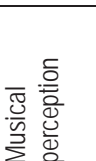 & 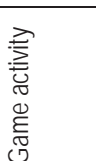 & 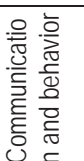 \\
\hline Junior preschool & 27,07 & 22,12 & 18,24 & 11,32 & 31,13 & 18,13 & 22,07 & 24,13 \\
\hline Middle preschool & 19,45 & 18,17 & 14,34 & 10,34 & 14,64 & 17,23 & 24,02 & 24,89 \\
\hline Senior preschool & 12,12 & 13,67 & 13,14 & 9,67 & 12,03 & 13,34 & 24,87 & 26,03 \\
\hline
\end{tabular}

It is obvious that in traditional conditions of the kindergarten a certain group of children does not cope with the program requirements of a preschool establishment, systematically experiences difficulties in learning the program material, as well as in the development of certain skills. The greatest number of children of each age period experience difficulties in learning the program material in such areas as speech development, construction, elementary mathematical representations and acquaintance with the surrounding.

The qualitative analysis of children's difficulties in learning the program material revealed that the software of "vulnerable" areas provides the development at children in the course of the educational activity of all informative processes, as well as the formation of the cerebration ways. And the insufficient level of the development of attention, thinking, memory, imagination, as well as the ability to compare, analyze, establish relationships of the cause and effect, to generalize cause various difficulties at children (Evilly, 2015).

In the age dynamics these difficulties decrease, whereas the difficulties of interpersonal communication, behavior and game activity increase. The interpersonal relations of children of this category are unstable. The interaction with contemporaries has a changeable, situational character. As a rule, children prefer to communicate with adults or with children who are younger than themselves. Communication with contemporaries has a limited character. In communication children show no activity.

The game activity of the children experiencing difficulties in learning the program material of a preschool educational institution is characterized by monotony, lack of creative approach to the idea and the plot of a game, poverty of imagination. There is also noted a short duration of the game action. The children do not begin independently the game activity and during the entire game action remain on a minor position, the game actions are characterized as displaying. The children follow the rules of the game indistinctly. In frustration situations the children manifest reactions of negativism, flash of verbal aggression, affective reactions.

For the purpose of studying the presented group of children we carried out a study permitting to define psychological and pedagogical features of children experiencing difficulties in learning the program material of a preschool educational institution. In the program of this study we selected the following units:

- cognitive sphere of children, attention function; 
- emotional and strong-willed sphere;

- $\quad$ sphere of motility;

- $\quad$ sphere of good breeding (internal culture of a personality and external culture of a personality);

- sphere of interpersonal relations.

Studying the cognitive processes (perception, memory, thinking, speech) and functions of attention was realized by means of a standardized complex of psycho-diagnostic techniques for preschool children. Under the standardized complex of psycho-diagnostic techniques it is understood the minimum in number of the included methods set, but at the same time necessary and sufficient to estimate all aspects, in the essential qualities and properties, the features of the child's mental development at this age. Some techniques estimating the of the child's cognitive sphere development are included in the proposed complex. Each of the proposed techniques estimates an appropriate property from a specific side and as a result there is an opportunity to obtain the complex, scalene characteristic of all the child's features. The used techniques permit to obtain the indices expressed in the ten-mark scale. For children of junior preschool age the indices which are in the range of $2 \ldots 3$ points testify to the normative level of the development of the appropriate mental function. For children of middle preschool age the point of the normative development of mental function makes from 4 to 5 points, and for children of senior preschool age it makes respectively $6 \ldots 8$ points.

The study of the children's perception included the following techniques:

- the technique "What is not enough?" - V-1;

- the technique "Learn who it is" - V-2.

The study of attention includes the following set of techniques:

- the technique "Find and delete" - VN-1;

- the technique "Put down icons" - VN-2.

The study of memory included the following techniques:

- $\quad$ the technique "Remember pictures" - P-1;

- $\quad$ the technique "Remember digits" - P-2.

The study of thinking included the techniques:

- the technique "Seasons" - M-1;

- $\quad$ the technique "That is superfluous here?".

The study of speech development included the following jobs:

- the technique "Call words" - R-1;

- the technique "Tell about the picture" - R-2.

The generalized data of the results of studying the features of the preschool cognitive sphere and function of attention development of a child experiencing difficulties in assimilating the preschool educational program are provided in Figure 1.

The generalized data of the children's cognitive sphere of the described category testify to the different level of lowering their cognitive processes. The analysis of protocols of testing permits to select the most typical features of the cognitive sphere of children.

1. The features of perception. The insufficient level of the perception development is revealed at $7.11 \%$ of junior preschool age children, $5.12 \%$ of middle preschool age children and 2,13\% of senior preschool age children. At the children of the considered category there is noted inaccuracy, fragmentariness and insufficient differentiation of perception. The focus of perception is reduced. The rate of this function is decelerated, there is reduced the speed of information reception and processing. In the perception of simple acoustical influences there are no difficulties, but in complicated conditions (fast speech, pronouncing words, polysyllabic and close in sounding words) the children experience difficulties in separation of sounds in the word. There is shown a larger than in the distant types of perception backing in the development of tactile perception. The children are at a loss in recognizing even well familiar subjects, in localizing tactile feelings, in reproducing the hands pose set by the adult.

2. The features of attention. The insufficient level of attention development is revealed at $37.87 \%$ of junior preschool age children, $35.22 \%$ of middle preschool age children and $34.43 \%$ of senior preschool age children. The children's attention experiencing difficulties in learning the program material is characterized with instability, increased distractibility level to irritants from the outside. The volume of attention is reduced. In activities there prevails involuntary attention. 


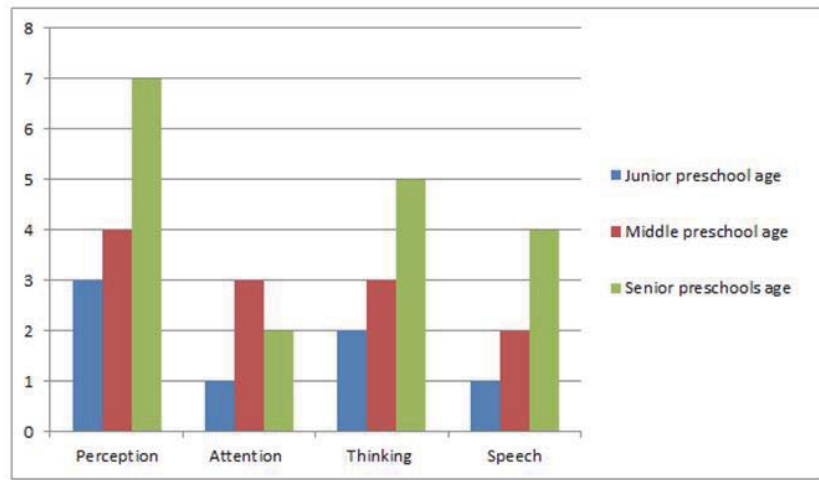

Figure 1 - The cognitive sphere and attention function development at children experiencing difficulties in learning the program material of a preschool educational establishment

3. The features of memory. The insufficient level of memory development is revealed at $32.13 \%$ of junior preschool age children, $30.02 \%$ of middle preschool age children and $29.43 \%$ of senior preschool age children. At the children of the studied category there is marked the reduced volume of short-term and longtime memory. Especially great difficulties are watched in remembering the verbal material. These reproductions are characterized with imperfectness and incompleteness. In reproducing the material there are marked inaccuracies and additions.

4. The features of thinking. The insufficient level of thinking development is revealed at $11.01 \%$ of junior preschool age children, $9.09 \%$ of middle preschool age children and $7.29 \%$ of senior preschool age children. At the preschool children experiencing difficulties in assimilating the preschool educational program there is observed the backing of the development of all types of thinking (evident and effective, evident and figurative and verbal). The considerable backing is found in manifestations of opportunity to realize opinions and conclusions. Alongside with this there is marked a slow rate of thinking processes. In execution of jobs the children need help from the outside. This help has an organizational character. In case of presenting modified jobs the children with difficulties in training can transfer the help to other conditions.

5. The features of speech development. The insufficient level of speech development is revealed at $37.43 \%$ of junior preschool age children, $36.72 \%$ of middle preschool age children and $30.06 \%$ of senior preschool age children. Speech opportunities of the children are characterized by the lowered active vocabulary, their passive vocabulary is behind the active one (the expressed discrepancy between the active and passive vocabulary is watched concerning adjectives, adverbs and participles). There is marked limitation of the words designating general concepts. The children's speech is not unfolded, syntax constructions of the used sentences are simplified. In word formation there often occur neologisms. Special difficulties are caused by the monologue. The dialogical speech proceeds in the question-answer form. The children's answers are terse.

Studying the emotional and strong-willed sphere of the children experiencing difficulties in learning the program material of a preschool educational institution was carried out by means of the following selection of techniques (Matveyeva, 2012): M.A. Panfilova's "Cactus", the color test of Lyusher, the frustration test of Rosenzweig, "Criteria of aggression at a child" by G.P. Lavrentyeva and T.M. Titarenko, "Uneasiness signs" by G.P. Lavrentyeva and T.M. Titarenko, determination of the mobilization level of will according to Sh.N. Chkhartashvili. The analysis of the results of studying the emotional and strong-willed sphere of children of the presented category revealed the following features: ease of changing mood and contrasting emotions (43.01\% - junior preschool age, 42.06\% - middle preschool age, 40.65\% - junior preschool age), emotional instability (67.09\% - junior preschool age, 57.12\% - middle preschool age, $44.32 \%$ - senior preschool age). Alongside with this there is marked some inadequacy and disproportion of emotional response to external situations (31.11\% - junior preschool age, $27.45 \%$ - middle preschool age, $27.12 \%$ - senior preschool age). The results of studying revealed: the increased uneasiness level (44.65\% - junior preschool age, 36,09\% - middle preschool age, $28.74 \%$ - senior preschool age), aggressions (23.32\% - junior preschool age, $34.05 \%$ - middle preschool age, $39.12 \%$ - senior preschool age).

Studying the motor sphere of the children experiencing difficulties in assimilating the preschool educational 
program permitted to establish a number of features in comparison with the norm. Shortcomings of the motility development in this category of children are shown in motive awkwardness, insufficient coordination of movements (57\%). At many children there is marked excessive physical activity (36\%). In certain cases physical activity is considerably reduced in relation to the normal level (21\%). A special difficulty is caused at children by arbitrary conscious movements directed at the achievement of a definite purpose. In executing some jobs there is marked carelessness, negligence, a slow rate of activities (88\%). A special difficulty is presented by the jobs connected to the small motor functions (84\%): execution of fine details of a picture, execution of graphic tests, fastening and unfastening buttons, lacing the details of clothes, etc.

For diagnostics of the personality's internal and external culture we developed a diagnostic map of good breeding of the child. The map consisted structurally of two tables: "Internal culture of the child's personality" and "External culture of the child personality". Each table respectively contained the indices of the integrated qualities of the child's personality. The indices of the personality's external culture were:

- observance of the standard rules of behavior;

- execution of adult's requirements;

- observance of hygienic skills;

- keeping neat appearance;

- $\quad$ keeping the workplace in order.

Respectively the indices of the child's internal culture were:

- $\quad$ ability to empathize with others (compassion);

- existence of a steady interest in new knowledge (inquisitiveness);

- $\quad$ readiness to help others (responsiveness);

- $\quad$ ability to solve independently an arisen problems (independence);

- $\quad$ ability to tell the truth (honesty) in different situations.

Studying the sphere of good breeding was carried out by cross comparing of estimates of the tutor's and parents' observation, as well as the method of a personal conversation with children. The integrative qualities of the child's internal and external culture were identical for all ages, but differed in the informative part. The informative filling of the method of studying the sphere of good breeding of children was built taking into account the child's age.

When estimating the sphere of good breeding of the child of the studied category there was introduced a quantitative system, i.e. 2 points: this quality is steady line of the child's identity (this quality is always present at the child), 1 point: this quality is not a steady line of the child's identity (the child's behavior do not always correspond to this quality, but there is a need to behave quite so), 0 points: this quality is unrepresentative for a child (the behavior of the child can sometimes correspond to this quality). On the basis of this system there was defined the good breeding level (internal culture of the child's identity and external culture of the child's identity): a high level of good breeding: $8 \ldots 10$ points; a middle level of good breeding: $4 \ldots 7$ points, a low level of good breeding: $0 \ldots 3$ points.

In Figure 2 there are provided the results of studying the sphere of good breeding of children of junior, middle and senior preschool age.

Having analyzed the data obtained, it is possible to draw the following conclusions. In a certain group of children of senior and middle preschool age experiencing difficulties in assimilating the preschool educational program, the level of internal and external culture is developed insufficiently, the studied qualities of the personality are unstable in the majority. At a certain group of children of the studied category of junior preschool age the levels of external and internal culture are low, respectively, and the studied qualities are often not developed.

When studying the sphere of the interpersonal relations of the children of preschool age there were used sociometric methods ("Ship Captain" method, "Two lodges" method) which permitted to reveal mutual (or not mutual) selective preferences of children. Children's answers (their negative and positive elections) were entered in a special protocol (matrix). The sum of the negative and positive elections obtained by each child permitted to reveal the situation in the group (the sociometric status) of children experiencing difficulties in assimilation of the preschool educational program: 


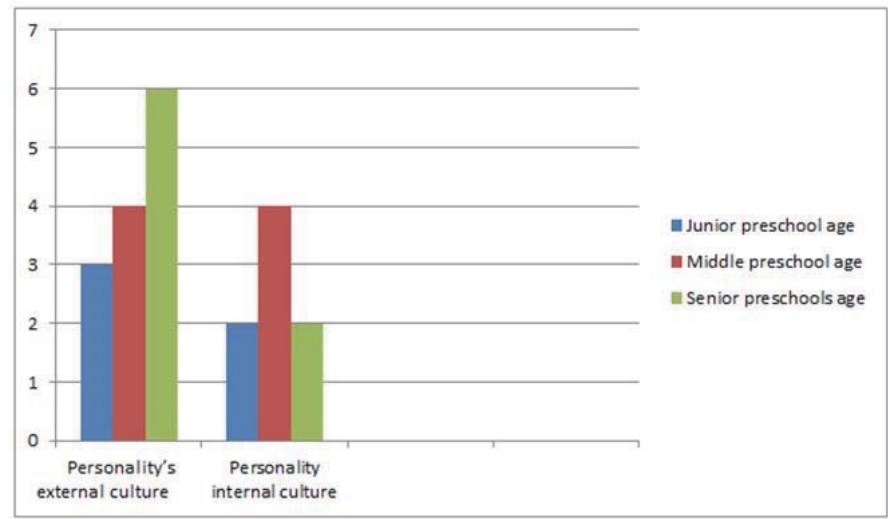

Figure 2 - Sphere of children's education level when experiencing difficulties in learning the program material

- $\quad$ the popular children, i.e. the children who received the greatest number of choices (in our case more than four) $-0 \%$ (junior, middle and senior preschool age);

- $\quad$ the preferred children, i.e. the children who received one or two positive choices $-10.09 \%$ (junior preschool age), $12.07 \%$ (middle preschool age), 11.98\% (senior preschool age);

- the ignored children, i.e. the children who received neither positive, nor negative choices (these children are unnoticed by their contemporaries) - 23.07\% (junior preschool age), $46.21 \%$ (middle preschool age), 59,34\% (senior preschool age);

- the rejected children, i.e. the children who received generally negative choices - $17.08 \%$ (junior preschool age), 28,96\% (middle preschool age), 30.01\% (senior preschool age).

\section{Results and Discussion}

Thus, studying the issue "Psychological and Pedagogical Aspects of Implementation of Personal Opportunities in Educational Operation with Children" permitted to draw certain conclusions.

At present a certain part of children systematically experiences difficulties in learning the program material in groups of children of mass preschool educational institutions.

The growth of the number of children experiencing different difficulties in learning the program material owing to their personal opportunities aggravated the problem of studying, training and educating this category of children.

The psychological and pedagogical study of this group of children revealed at them a different level of cognitive and emotional and strong-willed processes formation.

According to the mechanism of the child's cognition of the surrounding world (the knowledge of the world around occurs by means of cognitive actions which belong to different mental processes and lead to origin of the mental phenomena), variability of the mental processes development causes personal opportunities of the children in learning the program material of a preschool educational institution.

The insufficient level of the mental processes formation and, therefore a number of the children's problems at each of the stages of preschool age arising in the course of their education can have a reversible character (Vygotsky, 1991).

The overcoming of these problems is possible only under the condition of timely (prior to systematic training at school) identification of these children and rendering the purposeful pedagogical help at preschool age consisting in the accounting of these opportunities in the course of education of the latter.

\section{References}

Barandiaran A., Muela A., Lopez de Arana E. Exploratory behaviour, emotional wellbeing and childcare quality in preschool education // Anales de psicologia Volume: 31 Issue: 2 Pages: 570-578 Published: may 2015.

Bardyshevskaya M.K. Therapeutic role of supervision over development of children with affective behavioral complexes//Issues of Psychology, No. 3, 2014, p. 118-130.

Chova L.G, Martinez A.L, Torres I.C. "We communicate, create and share": the educational use of the classroom blog and 
wiki in preschool education // 5th international conference of education, research and innovation (iceri 2012), -Pages: 97-103, Published: 2012.

Evilly N. Investigating the place and meaning of 'physical education' to preschool children: methodological lessons from a research study // Sport education and society Volume: 20 Issue: 3 Pages: 340-360. - Published: apr. 32015.

Maryutina T.M. Psychophysiological aspects of the child development//School of Health. 1994. N 1. P. 105-117.

Matveyeva E.Yu., Korneyev A.A. Features of programming and control functions at the first-form pupils//lssues of Psychology, No. 6, 2012, p. 10-19.

Presser A.L., Clements M., Ginsburg H. Big Math for Little Kids: The Effectiveness of a Preschool and Kindergarten Mathematics Curriculum // Early education and development Volume: 26 Issue: 3 Pages: 399-426. - Published: apr. 3. - 2015.

Vygotsky L.S. Pedagogical psychology / Under the editorship of V.V. Davydov. M.: Pedagogics, 1991. 